\title{
Autism Spectrum Disorders in Children Exposed in Utero to Hyperemesis Gravidarum
}

\author{
Darios Getahun, MD, PhD, MPH ${ }^{1,2}$ Michael J. Fassett, MD ${ }^{3}$ Steven J. Jacobsen, MD, $\mathrm{PhD}^{1}$ \\ Anny H. Xiang, $\mathrm{PhD}^{1}$ Harpreet S. Takhar, $\mathrm{MPH}^{1}$ Deborah A. Wing, MD, MBA ${ }^{4,5}$ Morgan R. Peltier, PhD 6,7
}

1 Department of Research and Evaluation, Kaiser Permanente, Southern California, Pasadena

2 Department of Obstetrics, Gynecology, and Reproductive Sciences, Rutgers-Robert Wood Johnson Medical School, New Brunswick, New Jersey

${ }^{3}$ Department of Obstetrics and Gynecology, Kaiser Permanente West Los Angeles Medical Center, Los Angeles, California

4 Department of Obstetrics and Gynecology, University of California, Irvine, California

${ }^{5}$ Korn Ferry, Los Angeles, California

6 Department of Obstetrics and Gynecology, Winthrop University Hospital

Research Institute, Winthrop University Hospital, Mineola, New York

${ }^{7}$ Department of Obstetrics and Gynecology, Winthrop University

Hospital, Mineola, New York

Am J Perinatol 2021;38:265-272.
Address for correspondence Darios Getahun, MD, PhD, MPH, Department of Research and Evaluation, Kaiser Permanente Southern California, 100 South Los Robles Avenue, 2nd Floor, Pasadena, CA 91101 (e-mail: darios.t.getahun@kp.org).

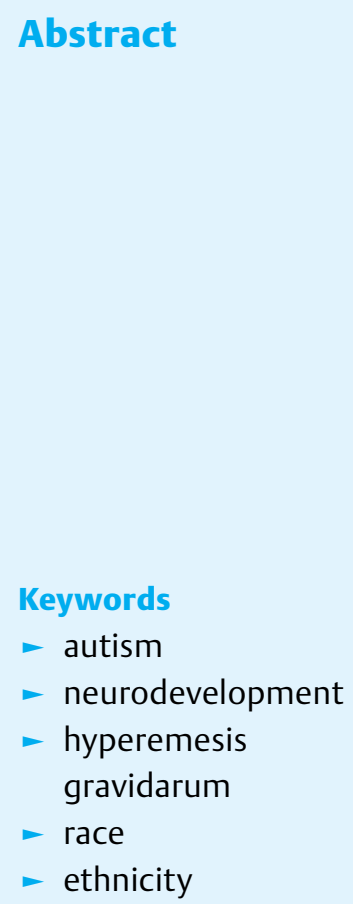

Objective This study aimed to determine if hyperemesis gravidarum (HG) is associated with autism spectrum disorder (ASD) risk, and how this association is influenced by race, ethnicity, sex, exposure timing, and medication used to treat it.

Study Design This is a retrospective cohort study using records from 469,789 mother-child pairs who delivered at Kaiser Permanente Southern California (KPSC) hospital (1991-2014). Singleton-born children were followed longitudinally from 2 to 17 years of age. Clinical records were used to determine the diagnosis of HG and specialist-confirmed diagnosis of ASD.

Results Children exposed to HG in-utero had higher rates of ASD than unexposed children ( 2.87 vs. $1.71 / 1,000$ person-years; adjusted hazard ratio [adj.HR]: $1.53 ; 95 \%$ confidence interval [Cl]: 1.37-1.70). Children exposed at first and second trimester of pregnancies were more likely to develop ASD; 1.58 -fold (95\% Cl: $1.40-1.79$ ), and 1.36fold (95\% Cl: $1.05-1.75)$, respectively, compared with unexposed children. HG was associated with ASD for boys (adj.HR: 1.50; 95\% Cl: 1.33-1.70) and girls (adj.HR: 1.62; $95 \% \mathrm{Cl}: 1.28-2.05)$. HG was significantly associated with ASD risk in white and Hispanic children. The medications used to treat HG did not contribute to ASD risk.

Conclusion HG diagnosis is associated with ASD risk and may be helpful in identifying at-risk children who could benefit from enhanced surveillance and earlier diagnosis and intervention.
Autism spectrum disorder (ASD) affects 1 in 68 children in the United States ${ }^{1}$ and its prevalence has dramatically increased over the last two decades. ${ }^{2,3}$ It persists into adulthood and is a significant burden to families and society. ${ }^{4,5}$ Although genetic and environmental factors have been suggested, though no specific cause of the condition has been identified, and it is thought to be a complex disorder of the developing brain with multifactorial etiology affecting the brain at critical times received

July 17, 2019

accepted

July 26, 2019

published online

October 3, 2019 (c) 2019. Thieme. All rights reserved.

Thieme Medical Publishers, Inc.,

333 Seventh Avenue, 18th Floor,

New York, NY 10001, USA
DOI https://doi.org/

10.1055/s-0039-1696670.

ISSN 0735-1631. 
during development. Potential risk factors include advanced parental age, white race, male sex, and multiple births. ${ }^{6-8}$ Antepartum and intrapartum conditions, ${ }^{9,10}$ preterm birth, ${ }^{11}$ small for gestational age birth, ${ }^{12}$ having a sibling with autism, ${ }^{13,14}$ and mood disorders in family members ${ }^{15}$ have also been suggested to increase risk.

Hyperemesis gravidarum (HG), a severe form of nausea and vomiting, affects 0.3 to $4 \%$ of pregnant women ${ }^{16-18}$ and can result in maternal weight loss, malnutrition, dehydration, and electrolyte/acid-base imbalance and low birthweight and small-for-gestational age birth of infant morbidity. ${ }^{16,19}$ Like autism, its pathoetiology is unknown but risk factors include family history, HG in a prior pregnancy, non-white race, female fetus, multiple gestation, and low body mass index. ${ }^{16,20-23}$ Previous studies suggest that metabolic problems, such as undernutrition, ${ }^{24,25}$ gestational diabetes mellitus (GDM), ${ }^{9}$ and hypothyroidism ${ }^{26}$ during early pregnancy may lead to neurodevelopmental conditions, such as schizophrenia and ASD. Therefore, we hypothesized that HG is associated with increased ASD risk in the children and that this association may be modified by child's sex, race/ethnicity, timing of first in utero exposure, severity of the condition, and gestational age at birth.

\section{Materials and Methods}

We conducted a retrospective longitudinal cohort study using medical records of pregnant women and their children ( $n=469,789$ ) born between January 1, 1991 and December 31, 2014 at all Kaiser Permanente Southern California (KPSC) hospital. To be eligible, children must have been born to KPSC-members, be a live-singleton birth between $28^{0 / 7}$ and $42^{6 / 7}$ weeks of gestation and be a KPSC health plan member for $\geq 3$ months between 2 and 17 years of age. The study cohort composition is shown in - Supplementary Appendix A: -Supplementary Fig. S1 (available in the online version). Children's medical records were linked longitudinally to biological mothers using unique identifiers. The linked medical records contain information on maternal sociodemographic and behavioral characteristics, maternal medical and obstetrical history, and complete child health care information. International Classification of Diseases, Ninth Revision, Clinical Modification (ICD-9-CM) codes from inpatient and outpatient physician encounters, as well as laboratory results and pharmacy records were used to ascertain the exposure and outcome of interest. Validation of the linked data have been reported in detail elsewhere. ${ }^{27}$ Institutional review board approval was obtained for this study.

The primary exposure of interest was the clinical diagnosis of HG (ICD-9-CM code 643.0x and 643.1x). To assess the effect of the severity of illness on ASD risk, we chose an approach with indicators of a more severe form of the condition that likely requires hospitalization. This approach used the following diagnoses and procedures: HG with metabolic disturbance (ICD-9-CM codes 643.1x and 99.18), requiring nasogastric enteral feeding (ICD-9-CM codes 96.07, and current procedural terminology [CPT] codes 43752 and 43760), and total parenteral nutrition (ICD-9-CM codes 96.07, 96.08, 96.6, 99.15, and 99.18).
To ascertain a diagnosis of ASD, we used the Diagnostic and Statistical Manual of Mental Disorders, Fourth Edition, Text Revision (DSM-IV-TR) ${ }^{28}$ for any of the following conditions: autistic disorder, childhood disintegrative disorder, Rett's disorder, Asperger's disorder, or pervasive developmental disorder, not otherwise specified. Children, ages between 2 and 17 years, with at least one documented DSM-IV-TR code for ASD on any two separate visits during the follow-up period formed the ASD cases. Clinical experts validated the accuracy of these codes through medical record review. ${ }^{29}$ As per KPSC guidelines, last revised April 2013, ${ }^{30}$ ASD services are covered by a plan (a child/adolescent psychiatrist, developmental/behavioral pediatrician, child psychologist, or neurologist). The experts are required to perform a series of behavioral and developmental surveillance at all well-child visits, as early as 4 months of age. If there is a sufficient degree of suspicion, a modified version of the checklist for autism in toddlers [M-CHAT] ${ }^{31}$ and developmental screening questionnaires for toddlers is completed (as early as 18 months of life). For each diagnosed child, a treatment plan is developed and provided by a qualified provider in autism services.

Potential confounders/modifiers in this study include child's race/ethnicity and sex, maternal age $(<25,25-34$, and $\geq 35$ years), education ( $<12,12$, and $\geq 13$ years), median family household income based on census tract of residence, timing of prenatal care initiation, smoking during pregnancy (yes/no), gestational age at delivery based on clinical estimates, and maternal comorbidities. Maternal and paternal race/ethnicity defined the child's race/ethnicity. A child was categorized nonHispanic white (white) if born to non-Hispanic white mother and father. The same applies to non-Hispanic black (black), Hispanic, and Asian/Pacific Islander race/ethnicity groups. The Other/Multiple race/ethnicity category includes children born from interracial/interethnic relationship. The electronic medical and pharmacy records contain detailed clinical and drugdispensing data on medications commonly used to treat mild form of $\mathrm{HG}$ (diphenhydramine, promethazine, ondansetron, and metoclopramide), nutritional interventions (nasogastric enteral feeding and total parenteral nutrition), and injection or infusion of electrolytes.

Follow-up of children started from the delivery date until the date of ASD diagnosis. Censoring occurred on the earliest of the following dates: health plan disenrollment, 17th birthday, non-ASD related death, or end of study (December 31,2016$)$. We examined the distributions of maternal and child characteristics by HG status using $\chi^{2}$ tests. HG may recur between pregnancies and ASD also tends to recur in siblings; such clustered observations are likely to be correlated. Therefore, to examine the association between prenatal exposure to HG and ASD, we used marginal Cox's proportional hazards model to account for within-cluster correlation. Confounding variables were chosen a priori or if they resulted in $p$-value $<0.05$.

Because the timing and severity of prenatal exposure, and the fact that child's sex and gestational age at birth may influence ASD risk, we stratified the data for these potential mediators (-Table 3; -Supplementary Appendix B: -Supplementary Fig. $\$ 2$ [available in the online version]). 
To assess the impact of the severity of illness on the association between prenatal exposure to HG and ASD, we compared the association of HG with metabolic disturbances to those without. We also examined the effect of HG treatments on the observed association for each level of disease-modifying therapy after limiting the analysis to pregnancies $(n=190,126)$ with complete medication data available during the study period (2006-2014). We performed the following sensitivity analyses (-Supplementary Appendix C: - Supplementary Table S1 [available in the online version]) to evaluate the relative influence of each parameter on the observed risk relationships: (1) exclude children with only one ASD diagnosis, (2) exclude children with a history of congenital anomalies and developmental and emotional comorbidities (mental retardation, developmental dyslexia, deficits in language processing, conduct disorder, irritability, bipolar or anxiety disorders, and depression), (3) exclude pregnancies with a history of medical and/or perinatal adversities including gestational hypertension, diabetes, intrauterine growth restriction (IUGR), and low birth weight, (4) limit the cohort to children aged $\geq 4$ years because children aged 2 to 3 years may have shorter follow-up period to capture events, (5) limit the cohort to children without genetic predisposition, (6) account for maternal comorbidities ( - Supplementary Table $\mathbf{2}$ [available in the online version]), (7) account for "year of birth," (8) account for maternal prepregnancy body mass index (BMI, kg/ $\mathrm{m}^{2}$ ) in the model, and (9) examine the potential effects of residual confounders on the observed association using a range of E-values for the overall result and the lower limits of their 95\% confidence intervals (CI) observed in Cox's regression models. ${ }^{32}$ The E-values were estimated using the online calculator for hazard ratios (HR) with an outcome prevalence of $<15 \%$. Crude and adjusted HR and $95 \% \mathrm{CI}$ were used to quantify the magnitude of associations. The analyses were performed using SAS version 9.4 (SAS Institute, Cary, NC).

\section{Results}

We identified 469,789 children, aged between 2 and 17 years, who were born singleton in all KPSC hospitals between January 1, 1991 and December 31, 2014 with at least 90 days active enrollment during the follow-up periods (1993-2016). During the study period, 8,447 (1.8\%) children were diagnosed with ASD. The mean age at first diagnosis was 6 years (standard deviation $[S D]=3.3$ ). The mean follow-up time was 10.4 years $(\mathrm{SD}=4.7)$ for children diagnosed with ASD.

Compared with women without a history of HG, women with a history of HG were more likely to be 20 to 29 years of age, have completed $\geq 12$ years of education, have a high-household income, be nulliparous, and not smoke during pregnancy (-Table 1). The rate of prenatal exposure to HG varied by child's race/ethnicity and sex. Black and Asian/Pacific Islander children were more likely to be exposed to HG. Girls were more likely than boys to be exposed. Exposed children were more likely to be born preterm than unexposed children.

Compared with unexposed children (1.71/1,000 personyears), the overall ASD incidence rate in exposed children was higher (2.87/1,000 person-years; adjusted HR: 1.53 ; $95 \% \mathrm{CI}$ :
1.37-1.70). This remained significant when HG diagnosis was made during the first (HR: $1.58 ; 95 \% \mathrm{CI}: 1.40-1.79$ ) and second (HR: $1.36 ; 95 \%$ CI: 1.05-1.75) trimesters of pregnancy ( - Table 2). Exposure to HG was associated with ASD risk, regardless of the severity of the exposure. Limiting the cohort to children aged 4 to 17 years had no effect on our findings.

The association between prenatal exposure to $\mathrm{HG}$ and childhood ASD was modified by gestational age at birth (-Table 3; - Supplementary Appendix B: - Supplementary Fig. $\mathbf{S 2}$ [available in the online version]). In term-born children, prenatal exposure to $\mathrm{HG}$ is associated with a 1.39-fold increased ASD risk (95\% CI: 1.23-1.56), with the greatest risk occurring after exposure in the first (HR: 1.44; 95\% CI: 1.26-1.64) and second (HR: 1.21; 95\% CI: 0.91-1.61) trimesters, although the latter did not attain statistical significance. In preterm children, ASD incidence rates were twice as common in the exposed (4.82/1,000 person-years) compared with unexposed $(2.27 / 1,000$ person-years) groups, with significantly increased risk during the first (HR: 1.95; 95\% CI: 1.35-2.72) and second (HR: 2.27; 95\% CI: 1.28-4.02) trimesters. When further stratified by severity of fetal exposure, risk did not differ substantially at preterm and term births. Analyses stratified by child sex indicated that in both boys (HR: $1.50 ; 95 \% \mathrm{CI}: 1.33-1.70$ ) and girls (HR: 1.62; 95\%CI: 1.28-2.05), HG exposure was associated with ASD risk and was the strongest when exposure occurred during the first two trimesters.

Our results indicated that commonly prescribed medication to treat mild forms of HG did not significantly affect ASD risk (-Table 4). On further examining the effect of immediate versus later in-hospital or outpatient care on ASD risk, we observed no significant difference between women who were admitted early versus late during their illness (HR: 1.24; 95\% CI: 0.69-2.24; $p=0.47$ ). However, we observed higher ASD risk (HR: $1.41 ; 95 \% \mathrm{CI}$ : $1.05-1.90 ; p=0.02$ ) among children of women who received electrolyte replacement. In this sample limited to recent birth years with complete data available, HG with metabolic disturbance is still significantly associated with ASD risk (HR: 1.33; 95\% CI: $1.11-1.60 ; p=0.002$ ); however, the magnitude of the effect is lower than that observed for the total sample.

ASD diagnoses occurred at younger ages in children exposed to HG prenatally than in those who were not (-Fig. 1A). Although, ASD risk was elevated in both boys and girls regardless of the severity of exposure, the relationship was strongest among girls (-Fig. 1B).

The incidence of ASD diagnosis was higher for HG exposed children of all racial-ethnic backgrounds. HG exposure was found to be significantly associated with ASD in whites (HR: 1.70; 95\% CI: 1.23-2.36) and Hispanics (HR: 1.76; 95\% CI: 1.41-2.18), but not in blacks (HR: $1.18 ; 95 \% \mathrm{CI}: 0.77-1.81$ ) and Asian/Pacific Islanders (HR:1.37; 95\% CI: 0.88-2.14).

The results of the sensitivity analyses after excluding children with only one ASD diagnosis, a history of developmental and emotional comorbidities, congenital malformation, excluding children aged $<4$ years, and accounting for "year of birth," family predisposition to ASD, and maternal medical and obstetrical comorbidities did not differ substantially from the overall 
Table 1 Distribution of maternal and child characteristics based on HG status

\begin{tabular}{|c|c|c|c|}
\hline Characteristics & No HG $n=455,263(\%)$ & HG $n=14,526(\%)$ & $p$-Value \\
\hline Maternal age $(y)$ & & & $<0.001$ \\
\hline$<20$ & $27,171(6.0)$ & $760(5.2)$ & \\
\hline $20-29$ & $196,748(43.2)$ & $7,348(50.6)$ & \\
\hline $30-34$ & $138,693(30.5)$ & $4,093(28.2)$ & \\
\hline$\geq 35$ & $92,651(20.4)$ & $2,325(16.0)$ & \\
\hline Maternal education (y) & & & $<0.001$ \\
\hline$<12$ & $46,726(10.3)$ & $992(6.8)$ & \\
\hline 12 & $128,537(28.2)$ & $4,459(30.7)$ & \\
\hline$\geq 13$ & $264,821(58.2)$ & $8,864(61.0)$ & \\
\hline Missing & $15,179(3.3)$ & $211(1.5)$ & \\
\hline Median household income, USD & & & $<0.001$ \\
\hline$<30,000$ & $45,228(9.9)$ & $1,105(7.6)$ & \\
\hline $30,000-49,999$ & $156,488(34.4)$ & $4,914(33.8)$ & \\
\hline $50,000-69,999$ & $135,396(29.7)$ & $4,432(30.5)$ & \\
\hline $70,000-89,999$ & $69,182(15.2)$ & $2,450(16.9)$ & \\
\hline$\geq 90,000$ & $46,127(10.1)$ & $1,569(10.8)$ & \\
\hline Nulliparous & $175,982(38.7)$ & $5,756(39.6)$ & $<0.001$ \\
\hline Smoking during pregnancy & $31,126(6.8)$ & $834(5.7)$ & $<0.001$ \\
\hline Late/no initiation of prenatal care & $45,935(10.1)$ & $766(5.3)$ & $<0.001$ \\
\hline Gestational age $<37$ weeks & $33,133(7.3)$ & $1,223(8.4)$ & $<0.001$ \\
\hline Child's Race/Ethnicity & & & $<0.001$ \\
\hline Non-Hispanic White & $98,328(21.6)$ & $2,336(16.1)$ & \\
\hline Non-Hispanic Black & $38,757(8.5)$ & $1,924(13.2)$ & \\
\hline Hispanic & $170,416(37.4)$ & $5,526(38.0)$ & \\
\hline Asian/Pacific Islander & $39,437(8.7)$ & $1,334(9.2)$ & \\
\hline Other/Multiple & $102,125(22.4)$ & $3,346(23.0)$ & \\
\hline Child' sex & & & $<0.001$ \\
\hline Female & $221,856(48.7)$ & $7,592(52.3)$ & \\
\hline Male & $233,407(51.3)$ & $6,934(47.7)$ & \\
\hline
\end{tabular}

Abbreviations: HG, Hyperemesis gravidarum; USD, United States dollar.

analysis (-Supplementary Appendix C: - Supplementary Table S1 [available in the online version]). Lastly, a sensitivity analysis using E-value to assess bias due to potential unmeasured confounders ${ }^{32}$ gave an E-value of 2.43 (95\% CI: 2.08-2.79) for the overall adjusted HR of 1.53 (95\%CI: 1.37-1.70). Thus, a minimum risk ratio of 2.08 would be required between unmeasured confounders and HG exposure, and between unmeasured confounders and ASD to explain away the significant association between HG and child ASD.

\section{Discussion}

In this study, we demonstrated that in utero exposure to $\mathrm{HG}$ is associated with increased risk of ASD that could not be explained by confounding factors. The magnitude of association did not vary with the severity of exposure and was strongest when the exposure occurred during the first two trimesters. Exposure to HG increases ASD risk, regardless of term or preterm birth with greatest risk in the first two-thirds of pregnancy. We also found that prenatal HG increased ASD risk in boys and girls and that there were significantly increased risks for whites and Hispanics. Commonly prescribed medication for mild forms of HG did not alter ASD risk.

We hypothesized that the effect of HG on ASD is highly dependent on the timing of fetal exposure to HG because previous studies demonstrated that poor maternal nutrition during early fetal life leads to long-term neurodevelopmental impairments. ${ }^{9,33-35}$ However, our inability to detect $\mathrm{HG}$ as a cause of ASD in the third trimester may also be due to greatly reduced rates of $\mathrm{HG}$ in that time. Moreover, adjusting for history of prenatal psychosocial disorders, a factor linked to cognitive impairments in children, ${ }^{36}$ did not affect the magnitude of association, suggesting an independent effect of HG on ASD risk. 
Table 2 Association between hyperemesis gravidarum and autism spectrum disorder

\begin{tabular}{|c|c|c|c|c|c|c|}
\hline \multirow[t]{2}{*}{ Hyperemesis Gravidarum status } & \multicolumn{2}{|l|}{ Number } & \multirow{2}{*}{$\begin{array}{l}\text { Incidence } \\
\text { rate }^{\mathrm{a}}\end{array}$} & \multicolumn{3}{|c|}{ Hazard ratios (95\% confidence Intervals) } \\
\hline & Total births & ASD & & Crude & Adjusted $^{\mathrm{b}}$ & $p$-Value \\
\hline No HG & 455,263 & 8115 & 1.71 & 1.0 (ref.) & 1.0 (ref.) & \\
\hline HG & 14,526 & 332 & 2.87 & $1.47(1.31-1.64)$ & $1.53(1.37-1.70)$ & $<0.001$ \\
\hline \multicolumn{7}{|l|}{ Trimester at first diagnosis } \\
\hline 1st trimester (weeks of gestation) & 11,505 & 269 & 2.94 & $1.50(1.33-1.71)$ & $1.58(1.40-1.79)$ & $<0.001$ \\
\hline 2nd trimester (weeks of gestation) & 2,785 & 59 & 2.68 & $1.36(1.05-1.76)$ & $1.36(1.05-1.75)$ & 0.02 \\
\hline 3rd trimester (weeks of gestation) & 236 & 4 & 1.80 & $1.01(0.38-2.69)$ & $1.06(0.40-2.83)$ & 0.91 \\
\hline \multicolumn{7}{|l|}{ Severity of illness ${ }^{c}$} \\
\hline HG without metabolic disturbance & 8,195 & 183 & 2.77 & $1.42(1.23-1.64)$ & $1.46(1.26-1.69)$ & $<0.001$ \\
\hline HG with metabolic disturbances & 6,331 & 149 & 3.00 & $1.53(1.30-1.80)$ & $1.63(1.38-1.92)$ & $<0.001$ \\
\hline
\end{tabular}

Abbreviations: ASD, autism spectrum disorders; HG, hyperemensis gravidarum.

ancidence rate is shown per 1000 person-years.

bHazard ratios (HR) were adjusted for maternal age, education, smoking during pregnancy, parity, prenatal care, maternal psychosocial disorder, child's sex, race/ethnicity, and year of diagnosis.

'Severe metabolic disturbances that require immediate clinical intervention (injection or infusion of electrolytes, nasogastric enteral feeding, or total parenteral nutrition).

Table 3 Associations between hyperemesis gravidarum and autism spectrum disorder by gestational age at birth and child's sex

\begin{tabular}{|c|c|c|c|c|c|c|c|c|c|c|c|c|}
\hline \multirow[t]{3}{*}{ Conditions } & \multicolumn{12}{|c|}{ Incidence rates $(\mathrm{IR})^{\mathrm{a}}$ and adjusted hazard ratios $(\mathrm{HR})^{\mathrm{b}}$ for ASD } \\
\hline & \multicolumn{3}{|c|}{ Preterm $(n=34,356)$} & \multicolumn{3}{|c|}{ Term $(n=435,433)$} & \multicolumn{3}{|c|}{ Female $(n=229,448)$} & \multicolumn{3}{|c|}{ Male $(n=240,341)$} \\
\hline & $\mathbf{I R}$ & HR $(95 \% \mathrm{Cl})$ & $p$-Value & IR & $\mathrm{HR}(95 \% \mathrm{Cl})$ & $p$-Value & $\mathbf{I R}$ & $\mathrm{HR}(95 \% \mathrm{Cl})$ & $p$-Value & $\mathbf{I R}$ & $\mathrm{HR}(95 \% \mathrm{Cl})$ & $p$-Value \\
\hline $\begin{array}{l}\text { No HG } \\
(n=455,263)\end{array}$ & 2.27 & $\begin{array}{l}1.00 \\
\text { (ref.) }\end{array}$ & & 1.67 & $\begin{array}{l}1.00 \\
\text { (ref.) }\end{array}$ & & 0.65 & $\begin{array}{l}1.00 \\
\text { (Ref.) }\end{array}$ & & 2.73 & $\begin{array}{l}1.00 \\
\text { (Ref.) }\end{array}$ & \\
\hline $\begin{array}{l}\text { HG } \\
(n=14,526)\end{array}$ & 4.82 & $\begin{array}{l}1.98 \\
(1.48-2.66)\end{array}$ & $<0.001$ & 2.69 & $\begin{array}{l}1.39 \\
(1.23-1.56)\end{array}$ & $<0.001$ & 1.20 & $\begin{array}{l}1.62 \\
(1.28-2.05)\end{array}$ & $<.001$ & 4.74 & $\begin{array}{l}1.50 \\
(1.33-1.70)\end{array}$ & $<0.001$ \\
\hline \multicolumn{13}{|c|}{ Timing of 1st HG diagnosis } \\
\hline $\begin{array}{l}\text { 1st trimester } \\
(n=11,505)\end{array}$ & 4.73 & $\begin{array}{l}1.95 \\
(1.35-2.72)\end{array}$ & $<0.001$ & 2.78 & $\begin{array}{l}1.44 \\
(1.26-1.64)\end{array}$ & $<0.001$ & 1.21 & $\begin{array}{l}1.64 \\
(1.26-2.12)\end{array}$ & $<.001$ & 4.94 & $\begin{array}{l}1.57 \\
(1.37-1.80)\end{array}$ & $<0.001$ \\
\hline $\begin{array}{l}\text { 2nd trimester } \\
(n=2785)\end{array}$ & 5.60 & $\begin{array}{l}2.27 \\
(1.28-4.02)\end{array}$ & 0.001 & 2.36 & $\begin{array}{l}1.21 \\
(0.91-1.61)\end{array}$ & 0.20 & 1.17 & $\begin{array}{l}1.57 \\
(0.91-2.72)\end{array}$ & 0.10 & 4.19 & $\begin{array}{l}1.31 \\
(0.98-1.75)\end{array}$ & 0.07 \\
\hline $\begin{array}{l}\text { 3rd trimester } \\
(n=236)\end{array}$ & 0.00 & - & - & 1.97 & $\begin{array}{l}1.19 \\
(0.45-3.16)\end{array}$ & 0.73 & 0.89 & $\begin{array}{l}1.36 \\
(0.19-9.66)\end{array}$ & 0.76 & 2.72 & $\begin{array}{l}0.99 \\
(0.32-3.06)\end{array}$ & 0.98 \\
\hline \multicolumn{13}{|c|}{ Severity of illness ${ }^{c}$} \\
\hline $\begin{array}{l}\text { HG-no } \\
\text { metabolic } \\
\text { disturbance }\end{array}$ & 4.57 & $\begin{array}{l}1.85 \\
(1.23-2.77)\end{array}$ & 0.003 & 2.62 & $\begin{array}{l}1.35 \\
(1.15-1.57)\end{array}$ & $<0.001$ & 1.58 & $\begin{array}{l}2.15 \\
(1.64-2.81)\end{array}$ & $<0.001$ & 4.09 & $\begin{array}{l}1.28 \\
(1.08-1.53)\end{array}$ & 0.01 \\
\hline $\begin{array}{l}\mathrm{HG}+ \\
\text { metabolic } \\
\text { disturbance }\end{array}$ & 5.10 & $\begin{array}{l}2.16 \\
(1.44-3.25)\end{array}$ & $<0.001$ & 2.78 & $\begin{array}{l}1.45 \\
(1.22-1.73)\end{array}$ & $<0.001$ & 0.68 & $\begin{array}{l}0.93 \\
(0.58-1.48)\end{array}$ & 0.76 & 5.62 & $\begin{array}{l}1.82 \\
(1.53-2.16)\end{array}$ & $<0.001$ \\
\hline
\end{tabular}

Abbreviations: ASD, autism spectrum disorders; $\mathrm{Cl}$, confidence interval; $\mathrm{HG}$, hyperemesis gravidarum..

${ }^{\mathrm{I}} \mathrm{R}$, incidence rate is shown per 1,000 person-years.

bHRs were adjusted for maternal age, education, smoking during pregnancy, perinatal care, parity, maternal psychosocial disorder, child's race/ ethnicity, and year of diagnosis.

'Severe metabolic disturbances that require immediate clinical intervention (injection or infusion of electrolytes, nasogastric enteral feeding, or total parenteral nutrition).

Although, there is increasing awareness of the fetal origins of adult disease, the long-term consequences of $\mathrm{HG}$ for the children are understudied. Malnutrition during pregnancy, even if limited to a few weeks or months, can lead to fetal nutrient deficiencies at a vulnerable period in organ development, increasing risk for long-term adverse health outcomes. ${ }^{37} \mathrm{HG}$, as a cause of maternal malnutrition in early pregnancy, may have a profound effect on fetal brain development either (1) directly, through metabolic imbalances resulted from maternal malnutrition and dehydration, ${ }^{38}$ or (2) indirectly, through hypoxemia and reduced nutritional supply to the fetus by compromising placental function. ${ }^{39,40}$

Women experiencing HG often have poor nutritional intake and are dehydrated, creating conditions that are 
Table 4 Hyperemesis gravidarum interventions and autism spectrum disorder in children born between 2006-2014

\begin{tabular}{|c|c|c|c|c|c|c|}
\hline \multirow[t]{2}{*}{ Treatment modalities } & \multicolumn{2}{|l|}{ Counts } & \multirow[t]{2}{*}{ Incidence rate ${ }^{a}$} & \multicolumn{2}{|c|}{ Hazard ratios $(95 \% \mathrm{Cl})$} & \multirow[t]{2}{*}{$p$-value } \\
\hline & Total birth & ASD & & Crude & Adjusted $^{\mathrm{b}}$ & \\
\hline No-HG & 179,602 & 3,555 & 3.16 & 1.00 (Ref.) & 1.00 (Ref.) & $(\text { Ref. })^{c}$ \\
\hline HG without metabolic disturbance & 5,538 & 117 & 3.12 & $1.07(0.89-1.28)$ & $1.13(0.94-1.36)$ & 0.20 \\
\hline No treatment & 2,425 & 51 & 2.76 & 1.00 (Ref.) & 1.00 (Ref.) & $(\text { Ref. })^{c}$ \\
\hline Diphenhydramine & 16 & 1 & 9.09 & $2.45(0.34-17.67)$ & $2.53(0.35-18.5)$ & 0.36 \\
\hline Promethazine & 1,067 & 15 & 2.18 & $0.93(0.59-1.46)$ & $0.96(0.60-1.52)$ & 0.85 \\
\hline Ondansetron & 1,624 & 25 & 3.67 & $1.04(0.72-1.49)$ & $1.01(0.70-1.46)$ & 0.95 \\
\hline Metoclopramide & 950 & 29 & 4.45 & $1.41(0.93-2.14)$ & $1.39(0.91-2.13)$ & 0.12 \\
\hline HG with metabolic disturbances ${ }^{d}$ & 4,986 & 121 & 3.97 & $1.24(1.03-1.48)$ & $1.33(1.11-1.60)$ & 0.002 \\
\hline Inpatient care for $\mathrm{HG}$ as principal diagnosis & 4,020 & 95 & 3.85 & $1.20(0.98-1.47)$ & $1.29(1.05-1.58)$ & 0.02 \\
\hline Treatment started on the day of diagnosis & 3,550 & 82 & 3.77 & 1.00 (Ref.) & 1.00 (Ref.) & $(\text { Ref. })^{c}$ \\
\hline Treatment started at $\geq 1$ day after diagnosis & 470 & 13 & 4.44 & $1.19(0.66-2.14)$ & $1.24(0.69-2.24)$ & 0.47 \\
\hline Total enteral/parenteral nutrition & 139 & 2 & 2.21 & $0.71(0.18-2.85)$ & $0.76(0.19-3.06)$ & 0.70 \\
\hline Electrolyte injection/infusion & 1,798 & 44 & 4.26 & $1.27(0.95-1.72)$ & $1.41(1.05-1.90)$ & 0.02 \\
\hline
\end{tabular}

Abbreviations: ASD, autism spectrum disorders; $\mathrm{Cl}$, confidence interval; $\mathrm{HG}$, hyperemesis gravidarum.

Note: Analysis was limited to pregnancies (2006-2014) with complete medication data available in electronic medical records $(n=190,126)$.

ancidence rate is shown per 1,000 person-years.

'Hazard ratios were adjusted for maternal age, education, smoking during pregnancy, perinatal care, parity, maternal psychosocial disorder, child's race/ethnicity, and year of diagnosis.

'(Ref.); reference for adjusted $p$-value test statistics for strata differences.

${ }^{\mathrm{d}} \mathrm{HG}$ with metabolic disturbances requiring medical interventions that included injection or infusion of electrolytes, nasogastric enteral feeding, or total parenteral nutrition.

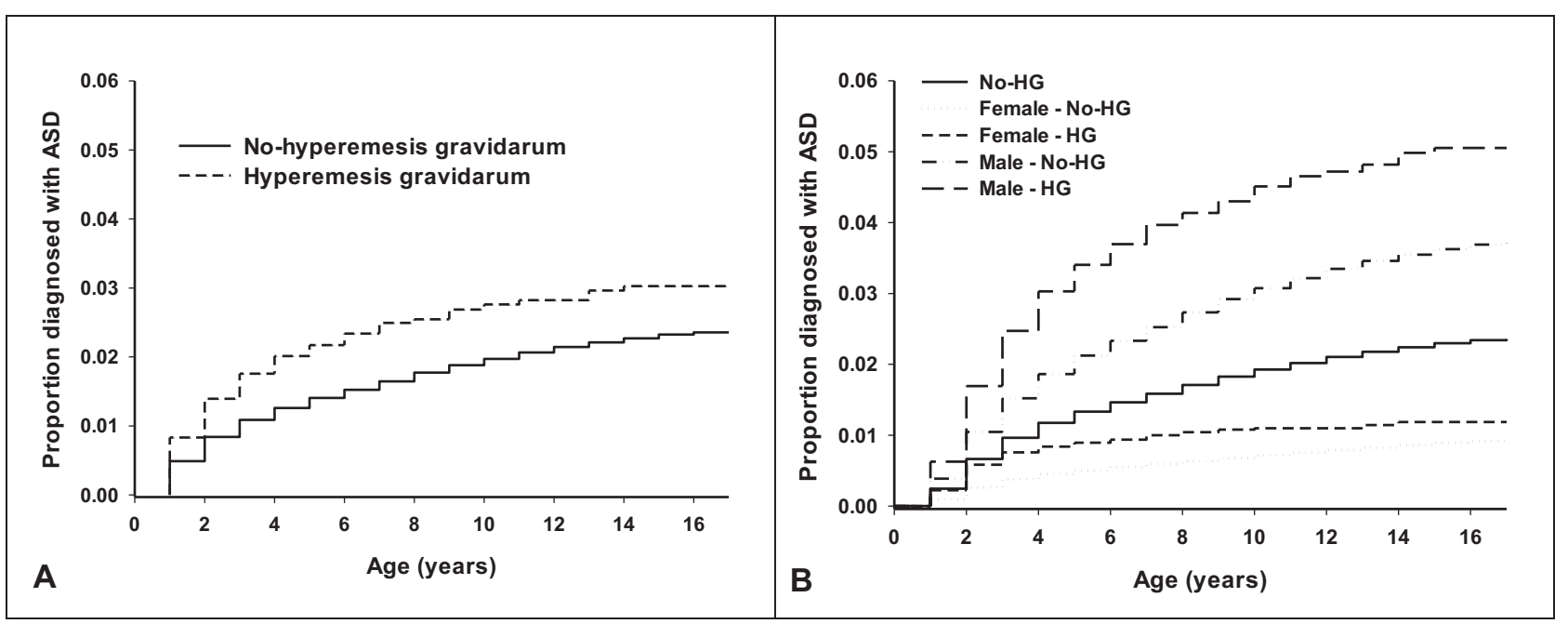

Fig. 1 Overall (A) and sex-specific (B) ASD survival curve by child age. Mean age (standard deviation [SD]) at ASD diagnosis as follows: no-HG total (5.15 [3.57]), HG total (3.87 [2.44]), no-HG male (5.12 [3.51]), HG male (4.00 [2.48]), no-HG female (5.28 [3.83]), and HG female (3.41 [2.24]). ASD, autism spectrum disorder; HG, hyperemesis gravidarum.

functionally similar to famine and may affect development in a similar manner. The best-known example is the Dutch Winter Hunger study, a natural experiment that utilized data collected on women that were forcibly deprived of food during the World War II. Caloric deprivation during the first two trimesters of pregnancy of these women increased cognitive disabilities and schizophrenia risk in the offspring. ${ }^{33}$ Other studies have shown this effect of undernutrition on cognitive impairment may continue throughout life. ${ }^{41}$ Our finding that HG during the first two trimesters increases the ASD risk is consistent with these previous reports. However, it is unclear how, or to what extent neurodevelopment is impaired by HG.

The placenta regulates the transfer of nutrients and oxygen from the mother to the developing fetus and can adapt morphologically and functionally to optimize nutrients and oxygen, promoting fetal organ development. Restriction of oxygen and protein clearly affects placental structure and vascularity. ${ }^{39}$ Animal $^{42,43}$ and human ${ }^{9,10}$ studies suggest that compromised placental function (as found in preeclampsia, GDM, and IUGR) is associated with ASD risk. Changes in placental function may also contribute to ASD development. The placenta produces 
several neurodevelopmental factors, such as nerve growth factor (NGF) and brain-derived neurotrophic factor (BDNF). ${ }^{40}$ BDNF regulates dopaminergic neuron development whose functions are disrupted in ASD and mental retardation. ${ }^{44,45}$ Limiting the data to pregnancies without placental abnormalities resulted in little effect on our overall findings. This suggests that HG may have specific effects on placenta function that result in ASD or that placental functions are largely unaltered but there are fewer nutrients to transport.

The KPSC health plan approach is comprehensive and more valid than parental reporting, nonspecialist diagnosis, or case identification from records because all ASD diagnoses are confirmed by a pediatric specialist. This limits the potential for patient misclassification. Furthermore, the large size and diverse population provide opportunities to explore how risks differ by the child's sex, race/ethnicity, gestational age or timing of $\mathrm{HG}$ exposure. The findings add to the strong evidence that the environment that babies are exposed to in the womb is a major cause of metabolic diseases in adults. We performed several sensitivity analyses to evaluate the independent effect of prenatal exposure to HG on the observed risk relationships. Although, the magnitude of the effect is slightly lower than that observed for the full sample, we still found an association between HG and ASD after limiting the sample to recent birth years (2008-2014) that had complete data on maternal prepregnancy BMI and comorbidities (-Supplementary Appendix C [available in the online version]).

This study has potential limitations. For example, diagnostic suspicion bias can occur when exposed and unexposed patients differ in measurement (both the intensity and diagnostic process) of health outcome statuses. Perinatal exposure to maternal smoking has been linked to behavioral and cognitive impairments in children ${ }^{46}$ and we relied on selfreported smoking during pregnancy. However, Buka, et al ${ }^{47}$ found strong agreement between self-reported smoking and serum cotinine levels. Some medications, such as antihistamines and promethazine, may have been prescribed to suppress allergy symptoms and information was not available regarding their intended use. Moreover, dosage data on prescribed medications and other factors (e.g., environmental toxins) were not available in the electronic medical records. To better understand the potential impact these and other unmeasured confounders may have, we calculated the E-value for the main result ( - Supplementary Appendix C [available in the online version]). Our finding suggests that the observed result would be explained by confounding bias only if the independent associations of the potential confounders with both the exposure and outcome of interest was of unrealistic magnitude (up to a 2.43-fold difference). Although causality cannot be proven based on this observational study, HG fulfills the Bradford-Hill criteria as a risk factor in terms of biological plausibility and timing.

\section{Conclusion}

Our findings provide additional evidence that the intrauterine environment has a significant impact on ASD risk. However, HG may stand out as a risk factor because it is clinically obvious and may be useful for identifying at-risk children that may benefit from closer surveillance and earlier diagnosis. Early intervention with behavioral and developmental therapy can result in better long-term cognitive and behavioral function, and improve symptoms. ${ }^{48}$ More aggressive diagnosis and treatment of HG may provide new opportunities to prevent this life-long disability and its impact on the families and society.

\section{Funding}

This study was supported in part by Kaiser Permanente Direct Community Benefit Funds. The opinions expressed are solely the responsibility of the authors and do not necessarily reflect the official views of the Kaiser Permanente Community Benefit Funds.

\section{Conflict of Interest}

None declared.

\section{Acknowledgments}

The authors thank Ms. Vicki Chiu for carrying out the initial analyses, and Dr. Sally F. Shaw and Mrs. Melissa Parra for their technical support.

\section{References}

1 Baio J, Wiggins L, Christensen DL, et al; Centers for Disease Control and Prevention. Morbidity and mortality weekly report. Prevalence of autism spectrum disorder among children aged 8 years Autism and Developmental Disabilities Monitoring Network, 11 Sites, United States, 2014. Surveillance Summaries 2018;67(06): $1-23$

2 Newschaffer CJ, Croen LA, Daniels J, et al. The epidemiology of autism spectrum disorders. Annu Rev Public Health 2007; 28:235-258

3 Biao J; Autism and Developmental Disabilities Monitoring Network Surveillance Year 2008 Principal Investigators; Centers for Disease Control and Prevention. Prevalence of autism spectrum disorders-Autism and Developmental Disabilities Monitoring Network, 14 sites, United States, 2008. MMWR Surveill Summ 2012;61(03):1-19

4 Montes G, Halterman JS. Association of childhood autism spectrum disorders and loss of family income. Pediatrics 2008;121 (04):e821-e826

5 Lavelle TA, Weinstein MC, Newhouse JP, Munir K, Kuhlthau KA, Prosser LA. Economic burden of childhood autism spectrum disorders. Pediatrics 2014;133(03):e520-e529

6 Croen LA, Grether JK, Selvin S. Descriptive epidemiology of autism in a California population: who is at risk? JAutism Dev Disord 2002;32(03):217-224

7 Kogan MD, Blumberg SJ, Schieve LA, et al. Prevalence of parentreported diagnosis of autism spectrum disorder among children in the US, 2007. Pediatrics 2009;124(05):1395-1403

8 Durkin MS, Maenner MJ, Newschaffer CJ, et al. Advanced parental age and the risk of autism spectrum disorder. Am J Epidemiol 2008;168(11):1268-1276

9 Xiang AH, Wang X, Martinez MP, et al. Association of maternal diabetes with autism in offspring. JAMA 2015;313(14):1425-1434

10 Getahun D, Fassett MJ, Peltier MR, et al. Association of perinatal risk factors with autism spectrum disorder. Am J Perinatol 2017; 34(03):295-304

11 Hall RW, Huitt TW, Thapa R, Williams DK, Anand KJ, Garcia-Rill E. Long-term deficits of preterm birth: evidence for arousal and attentional disturbances. Clin Neurophysiol 2008;119(06):1281-1291 
12 Moore GS, Kneitel AW, Walker CK, Gilbert WM, Xing G. Autism risk in small- and large-for-gestational-age infants. Am J Obstet Gynecol 2012;206(04):314e1-319

13 Xie F, Peltier M, Getahun D. Is the risk of autism in younger siblings of affected children moderated by sex, race/ethnicity, or gestational age? J Dev Behav Pediatr 2016;37(08):603-609

14 Grønborg TK, Schendel DE, Parner ET. Recurrence of autism spectrum disorders in full- and half-siblings and trends over time: a population-based cohort study. JAMA Pediatr 2013;167 (10):947-953

15 Vasa RA, Anderson C, Marvin AR, et al. Mood disorders in mothers of children on the autism spectrum are associated with higher functioning autism. Autism Res Treat 2012;2012:435646

16 Bailit JL. Hyperemesis gravidarium: epidemiologic findings from a large cohort. Am J Obstet Gynecol 2005;193(3, Pt 1): 811-814

17 Einarson TR, Piwko C, Koren G. Prevalence of nausea and vomiting of pregnancy in the USA: a meta analysis. JPopul Ther Clin Pharmacol 2013;20(02):e163-e170

18 Einarson TR, Piwko C, Koren G. Quantifying the global rates of nausea and vomiting of pregnancy: a meta analysis. J Popul Ther Clin Pharmacol 2013;20(02):e171-e183

19 Godsey RK, Newman RB. Hyperemesis gravidarum. A comparison of single and multiple admissions.J Reprod Med 1991;36(04):287-290

20 Fejzo MS, Ingles SA, Wilson M, et al. High prevalence of severe nausea and vomiting of pregnancy and hyperemesis gravidarum among relatives of affected individuals. Eur J Obstet Gynecol Reprod Biol 2008;141(01):13-17

21 Yoshimura M, Hershman JM. Thyrotropic action of human chorionic gonadotropin. Thyroid 1995;5(05):425-434

22 Schiff MA, Reed SD, Daling JR. The sex ratio of pregnancies complicated by hospitalisation for hyperemesis gravidarum. BJOG 2004;111(01):27-30

23 Cedergren M, Brynhildsen J, Josefsson A, Sydsjo A, Sydsjo G. Hyperemesis gravidarum that requires hospitalization and the use of antiemetic drugs in relation to maternal body composition. Am J Obstet Gynecol 2008;198(04):412-415

24 Brown AS, Susser ES, Lin SP, Neugebauer R, Gorman JM. Increased risk of affective disorders in males after second trimester prenatal exposure to the Dutch hunger winter of 1944-45. Br J Psychiatry 1995;166(05):601-606

25 Neugebauer R, Hoek HW, Susser E. Prenatal exposure to wartime famine and development of antisocial personality disorder in early adulthood. JAMA 1999;282(05):455-462

26 Román GC, Ghassabian A, Bongers-Schokking JJ, et al. Association of gestational maternal hypothyroxinemia and increased autism risk. Ann Neurol 2013;74(05):733-742

27 Getahun D, Rhoads GG, Fassett MJ, et al. Accuracy of reporting maternal and infant perinatal service system coding and clinical utilization coding. J Med Stat Inform 2013:1-3; doi:10.7243/20537662-1-3

28 American Psychiatric Association. Diagnostic and Statistical Manual of Mental Disorders, 4th Edition, Text Revision (DSM-IV-TR). Washington, DC: American Psychiatric Publishing; 2000

29 Coleman KJ, Lutsky MA, Yau V, et al. Validation of autism spectrum disorder diagnoses in large healthcare systems with electronic medical records. JAutism Dev Disord 2015;45(07): 1989-1996

30 Clinical Practice. Guideline. Kaiser permanent Southern California preventive services for children and adolescents. Available at: https://cl.kp.org/scal/home/refcontainerpage.dam.html?damref- path=/content/dam/clinicallibrary/scal/cpg/cpg/html/kpsc_preventive_care_child_adolescent_update.pdf. Accessed August 17 2019

31 Robins DL, Fein D, Barton ML, Green JA. The modified checklist for autism in toddlers: an initial study investigating the early detection of autism and pervasive developmental disorders. J Autism Dev Disord 2001;31(02):131-144

32 VanderWeele TJ, Ding P. Sensitivity Analysis in Observational Research: Introducing the E-Value. Ann Intern Med 2017;167 (04):268-274

33 Stein Z, Susser M, Saenger G, Marolla F. Famine and Human Development. The Dutch Hunger Winter of 1944-1945. New York, NY: Oxford University Press; 1975

34 Brown AS, van Os J, Driessens C, Hoek HW, Susser ES. Further evidence of relation between prenatal famine and major affective disorder. Am J Psychiatry 2000;157(02):190-195

35 Hulshoff Pol HE, Hoek HW, Susser E, et al. Prenatal exposure to famine and brain morphology in schizophrenia. Am J Psychiatry 2000;157(07):1170-1172

36 O'Connor TG, Heron J, Golding J, Glover V; ALSPAC Study Team. Maternal antenatal anxiety and behavioural/emotional problems in children: a test of a programming hypothesis. J Child Psychol Psychiatry 2003;44(07):1025-1036

37 Morgane PJ, Austin-LaFrance R, Bronzino J, et al. Prenatal malnutrition and development of the brain. Neurosci Biobehav Rev 1993;17(01):91-128

38 Madore C, Nadjar A, Delpech JC, et al. Nutritional n-3 PUFAs deficiency during perinatal periods alters brain innate immune system and neuronal plasticity-associated genes. Brain Behav Immun 2014;41:22-31

39 Bolin M, Åkerud H, Cnattingius S, Stephansson O, Wikström AK. Hyperemesis gravidarum and risks of placental dysfunction disorders: a population-based cohort study. BJOG 2013;120(05): 541-547

40 Mayeur S, Silhol M, Moitrot E, et al. Placental BDNF/TrkB signaling system is modulated by fetal growth disturbances in rat and human. Placenta 2010;31(09):785-791

41 de Rooij SR, Wouters H, Yonker JE, Painter RC, Roseboom TJ. Prenatal undernutrition and cognitive function in late adulthood. Proc Natl Acad Sci U S A 2010;107(39):16881-16886

42 Farias PS, dos S Souza K, Fioretto ET, dos Santos MR, Aires MB. Maternal diabetes affects rat placental morphology and pregnancy. Endocrine 2014;45(03):497-501

43 Heasman L, Clarke L, Firth K, Stephenson T, Symonds ME. Influence of restricted maternal nutrition in early to mid gestation on placental and fetal development at term in sheep. Pediatr Res 1998;44(04):546-551

44 Peng C, Aron L, Klein R, et al. Pitx3 is a critical mediator of GDNFinduced BDNF expression in nigrostriatal dopaminergic neurons. J Neurosci 2011;31(36):12802-12815

45 Miyazaki K, Narita N, Sakuta R, et al. Serum neurotrophin concentrations in autism and mental retardation: a pilot study. Brain Dev 2004;26(05):292-295

46 Hultman CM, Sparén P, Cnattingius S. Perinatal risk factors for infantile autism. Epidemiology 2002;13(04):417-423

47 Buka SL, Shenassa ED, Niaura R. Elevated risk of tobacco dependence among offspring of mothers who smoked during pregnancy: a 30year prospective study. Am J Psychiatry 2003;160(11):1978-1984

48 McEachin JJ, Smith T, Lovaas OI. Long-term outcome for children with autism who received early intensive behavioral treatment. Am J Ment Retard 1993;97(04):359-372 